\title{
As marcas de coerência e coesão na produção textual de jovens com síndrome de Down
}

\section{The marks of coherence and cohesion in the text production of young people with Down's syndrome}

\section{Las marcas de coherencia y cohesión en la producción textual de jóvenes con síndrome de Down}

\author{
Rayana Thyara de Lima Rêgo Ladeia ${ }^{1}$ (iD https://orcid.org/0000-0003-1031-8998 \\ Giulia Castellani Boaretto ${ }^{2}$ (iD) https://orcid.org/0000-0003-3726-2285 \\ Carla Salati Almeida Ghirello-Pires ${ }^{3}$ (iD https://orcid.org/0000-0001-7950-6001
}

\begin{abstract}
RESUMO: Este trabalho objetiva analisar as marcas de coerência e coesão na produção textual de jovens com síndrome de Down (SD), observando a continuidade, progressão, não contradição e articulação. O estudo foi efetuado com quatro jovens que frequentam o Laboratório de Pesquisa e Estudos em Neurolinguística da Universidade Estadual do Sudoeste da Bahia e participam do Grupo de Pesquisa "Fala Down". A produção textual consistiu em duas etapas: organização de gravuras e escrita do texto. A pesquisa está fundamentada na linguística textual e nos estudos sobre coerência e coesão realizados por Costa Val (2000, 2006), Charolles (1988) e Koch (2014). A análise dos dados priorizou a sequência lógica na organização das gravuras e os recursos linguísticos utilizados no texto. Os resultados evidenciam que as jovens organizaram o texto de forma coerente, mantendo a continuidade, progressão, não contradição e articulação. Apesar da carência de elementos linguísticos nas frases, não houve comprometimento no sentido geral da produção textual.
\end{abstract}

PALAVRAS-CHAVE: Coerência. Coesão. Síndrome de Down.

ABSTRACT: This paper aims to analyze the marks of coherence and cohesion in the textual production of young people with Down's syndrome (DS), observing continuity, progression, noncontradiction and articulation. The study was carried out with four young people who attend the

\footnotetext{
${ }^{1}$ Doutoranda em Linguística pela Universidade Estadual do Sudoeste da Bahia. E-mail: rayanaladeia@gmail.com 2Doutoranda em Linguística pela Universidade Estadual do Sudoeste da Bahia. E-mail: gcbmonitoria@gmail.com ${ }^{3}$ Doutora em Linguística pela Universidade Estadual de Campinas. Professora titular vinculada ao Departamento de Estudos Linguísticos e Literários e ao Programa de Pós-Graduação em Linguística da Universidade Estadual do Sudoeste da Bahia. Coordenadora do Projeto Fala Down. E-mail: carlaghipires@hotmail.com
} 
LADEIA, R. T. L.; BOARETTO, G. C.; GHIRELLO-PIRES, C. S. A.

Neurolinguistics Research and Studies Laboratory at the State University of Southwest Bahia and participate in the Research Group "Fala Down". The textual production consisted of two stages: organization of prints and writing of the text. The research is based on textual linguistics and on studies on coherence and cohesion carried out by Costa Val (2000, 2006), Charolles (1988) and Koch (2014). The analysis prioritized the logical sequence in the organization of the prints and the linguistic resources used in the text. The results show that the learners organized the text in a coherent way, maintaining continuity, progression and non contradiction, and articulation. Despite the lack of linguistic elements in the sentences, there was no interference in the general sense of textual production.

KEYWORDS: Coherence. Cohesion. Down's syndrome.

RESUMEN: Este trabajo tiene como objetivo analizarlas marcas de coherencia y cohesión la producción textual de jóvenes con síndrome de Down (SD), observando continuidad, progresión, no contradicción y articulación. El estudio se realizó con cuatro jóvenes que cursan el Laboratorio de Investigación y Estudios en Neurolingüística de la Universidad Estatal del Suroeste de Bahía y participar en el Grupo de Investigación "Fala Down". La producción textual constaba de dos etapas: organización de grabados y redacción del texto. La investigación se basa en la lingüística textual y en los estudios de coherencia y cohesión realizados por Costa Val $(2000,2006)$, Charolles (1988) y Koch (2014). El análisis de datos prioriza la secuencia lógica en la organización de las imágenes y los recursos lingüísticos utilizados en el texto. Los resultados muestran que las jóvenes organizaron el texto de forma coherente, manteniendo la continuidad, la progresión y la no contradicción y articulación. A pesar de la falta de elementos lingüísticos en las oraciones, no hubo compromiso en el sentido general de producción textual.

PALABRAS CLAVE: Coherencia. Cohesión. Síndrome de Down.

\section{Introdução}

O texto escrito possui uma função comunicativa e social específica, pois envolve duas pessoas: o autor e o leitor (ANTUNES, 2010). Os sentidos da produção escrita estão intimamente ligados ao processo dialógico estabelecido entre locutor e interlocutor, pois "um texto se constitui como tal no momento em que os parceiros de uma atividade comunicativa global são capazes de construir para ele determinado sentido" ( $\mathrm{KOCH}$, 2014, p.30). Compreende-se que a construção de um texto escrito perpassa pela internalização de diferentes normas do código linguístico, desde o entendimento do que é um texto até as unidades que fazem parte da sua composição.

Sendo assim, para elaborar um texto escrito, o autor recorre aos procedimentos de produção textual e de leitura, observando as características formais e funcionais específicas. Segundo Koch (2014), a produção textual ativa os artifícios cognitivos e metacognitivos a fim de alcançar os objetivos propostos para a atividade de interação verbal. Para que o texto seja um todo significativo, é necessário atender a alguns critérios: semântico-conceitual, que remete à coerência; formal, que está relacionado à 
coesão; e pragmático, que trata das questões informacionais e comunicativas. Esse conjunto de características é denominado de textualidade.

Neste estudo, priorizamos a coerência, a coesão e as relações de sentido estabelecidas a partir da seleção de palavras. Dessa forma, buscamos identificar no texto produzido por jovens com síndrome de Down (SD), se "os elementos subjacentes à superfície textual vêm a constituir, na mente dos interlocutores, uma configuração veiculadora de sentidos" (KOCH, 2014, p.52), permitindo a compreensão da sequência linguística e construção de uma unidade significativa por meio da continuidade, progressão, não contradição e articulação (CHAROLLES, 1988).

A coerência está vinculada ao aspecto comunicativo do texto. Já a coesão de um texto decorre de vários fatores que permitem as conexões linguísticas devido às ligações entre os elementos gramaticais, semânticos e discursivos (COSTA VAL, 2006). Sendo assim, uma boa construção textual depende da avaliação dos aspectos sintáticogramaticais, semânticos e pragmáticos que se relacionam no interior do texto e são fundamentais para a interlocução comunicativa.

Com base nas explanações realizadas a priori, percebemos que a produção textual coerente e coesa exige do autor o conhecimento sobre a linguagem, sendo que esta é decorrente das práticas sociais humanas. Desse modo, identificamos a dinamicidade na relação entre sujeito e linguagem, já que não é apenas o sujeito que interfere na linguagem, atribuindo-lhe continuamente a sua própria identificação a fim de despertar efeitos de sentido específicos, mas também é frequentemente modificado por ela, pois o que ouve ou lê pode influenciar no seu modo de agir ou de representar o mundo.

A linguagem é uma atividade do sujeito, o lugar de interação entre os membros de uma sociedade, que podem usá-la tanto para revelar como para esconder suas verdadeiras intenções. Contudo, no caso de pessoas com deficiência intelectual, mais especificamente pessoas com síndrome de Down, podemos encontrar, mesmo em se tratando de jovens ou adultos, uma discrepância no que seria esperado para o uso efetivo da linguagem, pois há um atraso global no desenvolvimento sendo que, para Gunn (1985) e Schwartzman (1999), a área da linguagem é a mais afetada. É preciso considerar que dentre as pessoas com SD existe uma ampla variabilidade, refletindo em seu aspecto cognitivo, pois, como todas as pessoas, elas estão sujeitas às situações ambientais e interacionais a elas oferecidas (GUNN, 1985). 
$\mathrm{O}$ atraso no processo de aquisição e funcionamento da linguagem, desse grupo que integra a população de pessoas com deficiência, pode ser observado tanto na recepção da linguagem quanto em sua expressão.Todavia, Horstmeier (1995) considera que as maiores dificuldades estão na sua capacidade expressiva, encontrando-se tanto nos níveis fonético/fonológico, quanto sintático/semântico e pragmático, justamente em níveis linguísticos que constituem a base de uma boa construção textual.

Nesse sentido, a estimulação e acompanhamento devem ser iniciados desde os primeiros meses para minimizar os comprometimentos no funcionamento da linguagem e potencializar a aprendizagem dessa população. Essas considerações nos permitem entender que as pessoas com síndrome de Down necessitam de um acompanhamento formal para que tenham condições de se expressarem de forma mais eficiente e produzir textos com a apresentação organizada de recursos linguísticos coesos que garantam a coerência.

É preciso pontuar que, ao analisarmos os estudos realizados no Brasil acerca da coerência e coesão nas produções escritas de pessoas com síndrome de Down, observamos uma escassa literatura, talvez pelo fato de muitos deixarem a escola antes mesmo de estarem alfabetizados e/ou concluírem o ensino médio com um nível elementar de alfabetização. Esses fatos convergem para que os aspectos linguísticos não se constituam enquanto objeto de estudo, o que influencia diretamente no processo de desenvolvimento de aquisição da escrita. A escrita não corresponde ao registro aleatório da fala, tendo em vista que seu surgimento está relacionado às necessidades comunicativas do ser humano $(\mathrm{KOCH}, 2014)$.

Sendo assim, este trabalho objetiva analisar as marcas de coerência e coesão na produção textual de quatro jovens com síndrome de Down. Para uma melhor compreensão do objeto de estudo, dividimos o artigo em seções: i) apresentação do texto como uma unidade de sentido, ii) incursão aos princípios de textualidade, iii) reflexões sobre linguagem escrita e a pessoa com síndrome de Down, iv) informações sobre os procedimentos metodológicos adotados, v) discussão dos dados gerados durante a pesquisa e, por fim, vi) conclusões acerca da coerência e coesão na produção textual de jovens com SD.

\section{Texto: uma unidade de sentido}


É comum ouvirmos a palavra texto tanto nos contextos escolares quanto não escolares. Segundo Antunes (2010, p.29), "texto é tudo que falamos ou escrevemos em situações de comunicação", ou seja, o aspecto predominante para essa caracterização é a comunicação imediata. A todo instante o homem produz textos com o objetivo de informar, distrair, justificar, persuadir, divergir, opinar etc. $O$ texto constitui um produto significativo produzido com uma intenção específica, para tanto as sentenças não podem representar apenas uma ordenação de palavras aleatórias. Para Bernárdez (1982, p.85):

[...] texto é a unidade linguística comunicativa fundamental, produto da atividade humana, que possui sempre caráter social; está caracterizado por seu estrato semântico e comunicativo, assim como por sua coerência profunda e superficial, devido à intenção do falante de criar um texto íntegro, e à sua estruturação mediante dois conjuntos de regras: as próprias de nível textual e as do sistema da língua.

Assim, entendemos que a atividade de produção de texto é inerente ao homem, tendo em vista que este utiliza esse recurso para se comunicar com o outro desde os tempos remotos. $O$ indivíduo emprega palavras e signos para expressar as suas ideias e, para isso, faz-se necessário seguir as regras que envolvem o nível textual e linguístico.

$O$ texto "é a unidade de manifestação da linguagem" (MARCUSCHI, 2012, p.72), ou seja, é por meio dele que a linguagem se materializa. O significado do texto caracteriza-se por ser resultado de processos de interação entre leitor e autor, por meio dos quais os esquemas comunicativos são negociados ( $\mathrm{KOCH}, 2014)$. O texto é produzido em um espaço e tempo específicos (contexto) que influenciam diretamente no produto final. Além disso, a produção textual envolve quem fala (escritor), para quem se fala (leitor) e suas intenções (objetivo), por isso é importante observar todas essas informações no momento da interpretação.

O sentido de um texto decorre de um mecanismo de articulação. No momento em que pensamos na articulação, devemos perceber o texto como uma estrutura em que há diversas partes que se relacionam umas com as outras. Essas relações se estabelecem em dois planos: o do conteúdo (ideias) e da amarração (relações linguísticas) e, por isso, devem ser percebidos no sentido global e analítico.

Com o surgimento da Linguística Textual, por volta da década de 60, o texto passou a ser estudado para além das palavras e frases, pois começou a ser "considerado a unidade básica de manifestação da linguagem, visto que o homem se comunica por 
LADEIA, R. T. L.; BOARETTO, G. C.; GHIRELLO-PIRES, C. S. A.

meio de textos e que existem diversos fenômenos linguísticos que só podem ser explicados no interior do texto" ( $\mathrm{KOCH}, 2014, \mathrm{p} .11)$, ou seja, os fatores sociais e ideológicos estão intimamente relacionados aos fatores linguísticos.

O texto não constitui apenas a união de sinais gráficos que se reúnem na formação de um todo, pois, para que cumpra o seu papel social é preciso estar ciente de que "os elementos linguísticos nele presentes formam apenas parte do conjunto dos fatores que Ihe conferem sentido e relevância" (ANTUNES, 2009, p.77). Portanto, a qualidade do texto depende da correlação do linguístico e extralinguístico.

Diante do exposto, ressaltamos a importância do texto como "ponto de encontro" entre locutor e interlocutor que na relação interativa promovem, sinalizam e determinam o sentido da linguagem em seu uso social (ANTUNES, 2010).

\section{Princípios de textualidade para um texto coerente e coeso}

Para que haja o encadeamento das ideias em um texto é necessário que não existam contradições entre as partes textuais, tendo em vista que cada uma delas constitui um pressuposto de outra, que será dita posteriormente, contribuindo para que o texto se organize de modo harmônico $(\mathrm{KOCH}, 2014)$. A garantia dessa concatenação de ideias confere ao texto a coerência, pois há uma combinação lógica entre os elementos.

Dessa forma, a coerência textual relaciona-se ao arranjo global que assegura um início, um meio e um final, a partir da escolha da linguagem em consonância com o tipo textual. Assim, as palavras utilizadas são cuidadosamente escolhidas para que haja a garantia de sentido.

Essa concatenação das ideias é alcançada por meio da conexão linguística que é a coesão. As relações linguísticas são estabelecidas a partir, por exemplo, dos pronomes, advérbios, sinônimos que funcionam como elementos de coesão e estabelecem relações lógicas entre os trechos do texto ou referenciam outros elementos presentes na estrutura textual. Sendo assim, a amarração de um texto é resultante do uso apropriado desses elementos.

O sentido de um texto decorre de um mecanismo de articulação. Ao pensar em articulação, devemos perceber o texto como uma estrutura em que há diversos 
segmentos todos relacionados uns com os outros. Para Antunes (2009, p.51):

[...] o texto envolve uma teia de relações, de recursos, de estratégias, de operações, de pressupostos que promovem a sua construção, que promovem seus modos de sequenciação, que possibilitam seu desenvolvimento temático, sua relevância informativo-contextual, sua coesão e sua coerência, enfim.

Compreendemos que a qualidade semântica e linguística do texto envolverá uma série de aspectos que culminarão em uma composição coerente e coesa. Corroborando com os estudos de Charolles (1988), Costa Val (2006) defende que a coerência e a coesão de um texto podem ser avaliadas a partir de quatro princípios de textualidade: continuidade, progressão, não contradição e articulação.

A continuidade ocorre no momento em que retomamos informações no decorrer do texto, permitindo que essas escolhas confiram uma unidade ao todo. Costa Val (2006, p.21) expõe que "no que se refere à coerência, esse requisito se manifesta pela retomada de conceitos e ideias; no âmbito da coesão, através do uso de recursos linguísticos específicos tais como a repetição de palavras", isto é, a coerência do texto é garantida com os elementos de coesão.

Já a progressão, ocorre quando há um acréscimo de informações a partir da retomada de elementos presentes no texto. Segundo Costa Val (2006), na coerência, a partir da ampliação dada às ideias apresentadas e, na coesão, pela apresentação de artifícios linguísticos que se demonstram em tópico, informação dada, comentário, informação nova, ou seja, a retomada de elementos anteriores permitirá a inserção de informações novas.

A não contradição "diz respeito à lógica interna do texto, explicitando a expectativa comum e normal de que o texto não se contradiga negando o que afirmou ou afirmando o que negou" (COSTA VAL, 2006, p.24). Portanto, a utilização de pronomes, verbos, advérbios deve seguir a posição do enunciador, permitindo que o leitor faça pressuposições e inferências com base no que está dito.

Por fim, temos a articulação que corresponde "à maneira como os fatos e conceitos apresentados no texto se encadeiam, como se organizam, que papéis exercem uns com relação aos outros e que valores assumem uns em relação aos outros" (COSTA VAL, 2006, p.27). A utilização de articuladores e conectivos permite que as relações semânticas entre as orações sejam possíveis que a escolha desses elementos linguísticos esteja 
LADEIA, R. T. L.; BOARETTO, G. C.; GHIRELLO-PIRES, C. S. A.

relacionada ao gênero textual e aos objetivos do produtor no momento da escrita.

Desse modo, concluímos que um texto se faz na inter-relação da dimensão linguística e da dimensão semântica, por isso, é tão importante observar a tessitura interna do texto e sua composição sintático-semântica, a fim de que seja possível estabelecer os sentidos produzidos, por meio da articulação dos enunciados.

\section{A linguagem escrita e a pessoa com síndrome de Down}

A síndrome de Down é uma condição genética que decorre da trissomia do par 21 considerada, na atualidade, uma das principais causas de deficiência intelectual (GHIRELLO-PIRES; LABIGALINI, 2011). Foi descrita pela primeira vez pelo médico Dr. John Longdan Down em 1866, entretanto, a descoberta da condição genética só ocorreu em 1959 pelo geneticista francês Jerome Legeune, diretor do departamento de genética da Universidade (SCHWARTZMAN, 1999).

Tristão e Feitosa (1998) elenca alguns fatores que interferem no comportamento linguístico de bebês com SD, a saber: limitações do desenvolvimento cognitivo, alterações no funcionamento neurológico, distúrbio de audição, além de alterações no desenvolvimento motor. Outro aspecto que temos que considerar é a situação relacional, ou seja, a possibilidade de interação com seus coetâneos e/ou adultos competentes em suas capacidades linguísticas fornecendo modelos de produção de linguagem, em situações dialógicas, que infelizmente ocorrem em número bem mais reduzido do que em crianças e jovens que não apresentam a trissomia. Levando em consideração que o processo de apropriação de linguagem, e mais especificamente a escrita, foco deste artigo, perpassa pelo desenvolvimento global do indivíduo, os fatores acima citados poderão resultar em atrasos e dificuldades na compreensão, expressão e funcionalidade da linguagem em pessoas com SD.

Horstmeier (1995) afirma que crianças e adultos com SD apresentam comprometimento na produção de sentenças corretas de acordo às normas gramaticais. Na concepção da autora, tanto a ordem incorreta das palavras como a dificuldade na formação de sentenças completas podem prejudicar o significado da mensagem que pessoas com SD desejam transmitir.

Nas observações de Ghirello-Pires e Labigalini (2011), os sujeitos com SD apresentaram 
dificuldades em manejar os eixos de seleção e combinação. As autoras apontam o uso quase que exclusivo do eixo de seleção em detrimento do eixo de combinação, culminando no que é conhecido como "estilo telegrafico", ou seja, a falta de elementos de ligação entre os elementos da oração. No entanto, as autoras evidenciam que esse funcionamento deve ser interpretado como um processo intermediário que ocorre com todas as crianças, com ou sem deficiência, no processo de aquisição da escrita.

O estilo telegráfico, ou seja, a omissão de elementos linguísticos nas sentenças, não pode ser entendido como mero apagamento, mas sim uma limitação na organização e vínculo entre as palavras, sendo comumente encontrado em textos iniciais de crianças em processo de alfabetização (ABAURRE; COUDRY, 2008).

Ghirello-Pires e Labigalini (2011) destacam ainda que é preciso fazer uma distinção entre estilo telegráfico e agramatismo. No primeiro caso, o sujeito, por razões diversas, economiza na linguagem como é feito em telegramas, mas pode explicitar quando lhe é solicitado ou mesmo se apropriar dos elementos faltantes caso lhe seja especificado. No segundo caso, diferentemente do primeiro, o sujeito encontra uma enorme dificuldade para expressar as combinações e suas relações numa determinada ordem sintagmática. No caso de pessoas com síndrome de Down, a pouca literatura existente na área aponta como justificativa para a produção de estilo telegráfico as falhas no mecanismo lexical (MILLER, 1996) e/ou os déficits na memória auditiva (TRISTÃO; FEITOSA, 1998).

Na pesquisa realizada por Gomes (2013), foi avaliada a coerência textual por meio de reescritas do conto de Rapunzel. Participaram do estudo nove alunos, seis com síndrome de Down (Grupo I) e os outros três sem deficiência (Grupo II). Gomes (2013) pôde aferir, por meio dos dados coletados, que o grupo de pessoas sem deficiência demonstrou maior competência para mobilizar os diferentes recursos cognitivos necessários para articular as informações no texto. Os sujeitos com SD apresentaram maiores dificuldades para elaborar desfechos quanto às ideias, demonstrando compreensão episódica dos eventos narrativos. Na análise realizada pela pesquisadora, as dificuldades encontradas se relacionam a não fixação de caracteres, como personagens e ações, o que compromete o sentido global do texto.

Apesar das diferenças encontradas por Gomes (2013) entre os grupos, foi possível observar que os alunos com SD não tiveram dificuldades para definir e manter a personagem principal no decorrer da história. A pesquisadora afirma que por mais que 0 
LADEIA, R. T. L.; BOARETTO, G. C.; GHIRELLO-PIRES, C. S. A.

grupo de alunos com SD tenha apresentado maiores dificuldades, quanto à ação de articulação das ideias, demonstraram estar em processo de construção, não apresentando aspectos específicos em seu curso de aprendizagem. Dessa forma, os dados do estudo corroboram com os dados obtidos por Ghirello-Pires e Labigalini (2011), já que não existem processos distintos de aquisição de escrita entre pessoas com ou sem síndrome de Down, apenas o tempo de permanência em cada etapa será maior perante a condição da SD.

\section{Procedimentos metodológicos}

A pesquisa foi realizada com quatro jovens com SD e os critérios de seleção dos sujeitos foram: 1) sexo feminino e 2) domínio de leitura e escrita. As jovens frequentam o Laboratório de Pesquisa e Estudos em Neurolinguística (LAPEN) da Universidade Estadual do Sudoeste da Bahia e participam do Grupo de Pesquisa "Fala Down" que se reúne semanalmente. Os encontros são mediados pelas colaboradoras/pesquisadoras que propõem atividades para o desenvolvimento da linguagem oral e escrita dos participantes, bem como abordam temas ligados à participação social e autonomia dos jovens com SD.

É importante destacarmos que o encontro foi filmado a fim de garantir a observação de todos os detalhes que perpassaram a realização da atividade. A pesquisa foi aprovada pelo Comitê Ética e Pesquisa da Universidade Estadual do Sudoeste da Bahia (CAAE 30053220.1.0000.0055), seguindo as exigências estabelecidas pelo Ministério da Saúde sobre ética em pesquisa com seres humanos, Resolução no 510/16 - Pesquisas nas áreas de Ciências Humanas e Sociais Aplicadas.

A coleta de dados aconteceu em uma sessão de atendimento em grupo ${ }^{4}$, com duração de 60 minutos. As participantes da pesquisa são identificadas no decorrer deste texto com as letras iniciais do nome e sobrenome. As quatro jovens possuem formação acadêmica, a saber: i) ensino superior completo (AA), ii) ensino superior incompleto (LA) e (MM) e, por fim, iii) ensino fundamental incompleto (MO).

Inicialmente, apresentamos o objetivo da atividade e explicamos que a construção

\footnotetext{
${ }^{4}$ Nas sessões de atendimento em grupo são realizadas atividades que visam o desenvolvimento da linguagem oral e escrita dos jovens que participam do Grupo de Pesquisa "Fala Down". As sessões são previamente agendadas e ocorrem no Laboratório de Pesquisa e Estudos em Neurolinguística.
} 
do texto ocorreria em duas etapas: ordenação das imagens e produção textual escrita. Dessa forma, as quatro jovens formaram duas duplas pelo critério de afinidade e cada uma recebeu um envelope com nove imagens que estavam desordenadas. Após a discussão da sequência das gravuras, narraram por escrito o que o conjunto de imagens mostrava.

O respectivo trabalho se baseou na abordagem qualitativa de pesquisa (MINAYO, 2008) por acreditar que esse método é o que melhor se adequa às pesquisas sociais e pode contribuir de forma significativa para esse tipo de estudo, uma vez que permite ao pesquisador interpretar os fenômenos, não deixando as informações encontradas somente no campo das aparências, mas explicando-as em sua essência. Dessa forma, ajudou a evidenciar as respostas buscadas, permitindo uma maior ênfase nos seus significados.

A abordagem qualitativa proporciona às pesquisas sociais maiores informações, por admitir que o pesquisador investigue o objeto em seu ambiente natural, descrevendo-o, levando em conta o seu processo e não apenas os resultados. A pesquisa qualitativa permite a análise do sujeito em situações dinâmicas da vida cotidiana (MINAYO, 2008).

Durante a realização das atividades, percebemos que as duplas organizaram as gravuras e, após a discussão, fizeram algumas trocas de posição de modo que garantisse uma ordem lógica das ações expressas. Após a conclusão da atividade, cada dupla realizou a leitura do texto e justificou algumas ideias apresentadas.

Dessa forma, os dados foram analisados a partir da linguística textual e dos pressupostos apresentados por Costa Val $(2000,2006)$, Charolles (1988) e Koch (2014) acerca da coesão e da coerência textual. No que diz respeito à coerência e à coesão, observamos a continuidade, a progressão, a não contradição e a articulação.

\section{Resultados e discussão}

A discussão dos textos produzidos pelas participantes da pesquisa, AA, MM, LA e MO, priorizou as marcas de coerência e coesão na produção textual de jovens com síndrome de Down, observando a continuidade, progressão, não contradição e articulação. Vejamos abaixo a organização das imagens (Figura 1) e a produção textual (Figura 2) realizadas por AA e MM, como também as figuras 3 e 4 com a organização de imagens e produção textual de LA e MO: 
Figura 1 - Organização das imagens

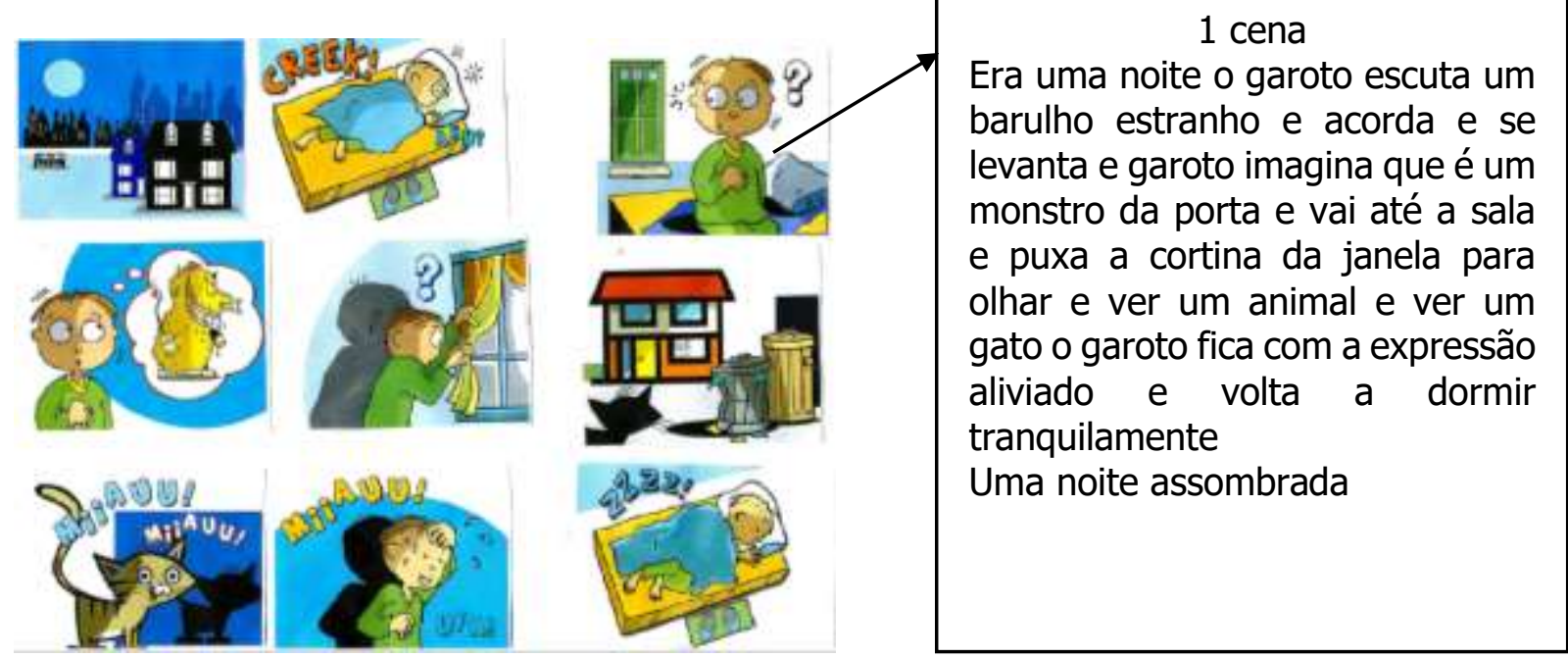

Fonte: Arquivo das pesquisadoras (2020).

Figura 2 - Produção textual

\section{$\sin \alpha$}

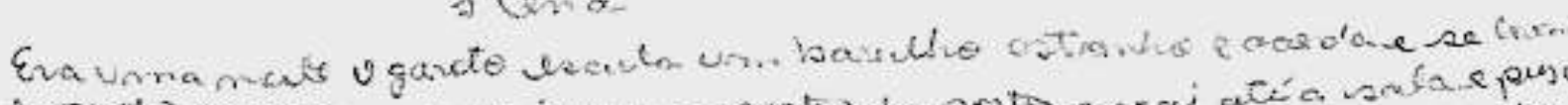

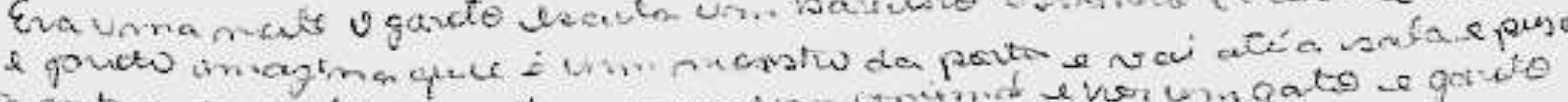

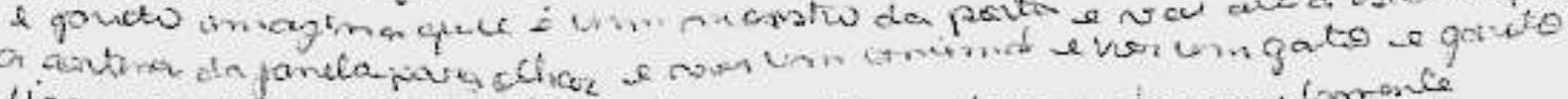

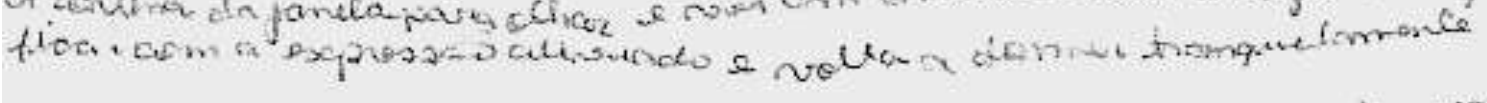

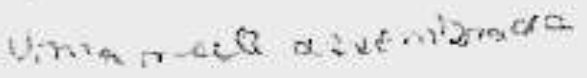

Fonte: Arquivo das pesquisadoras (2020).

Figura 3 - Organização das imagens
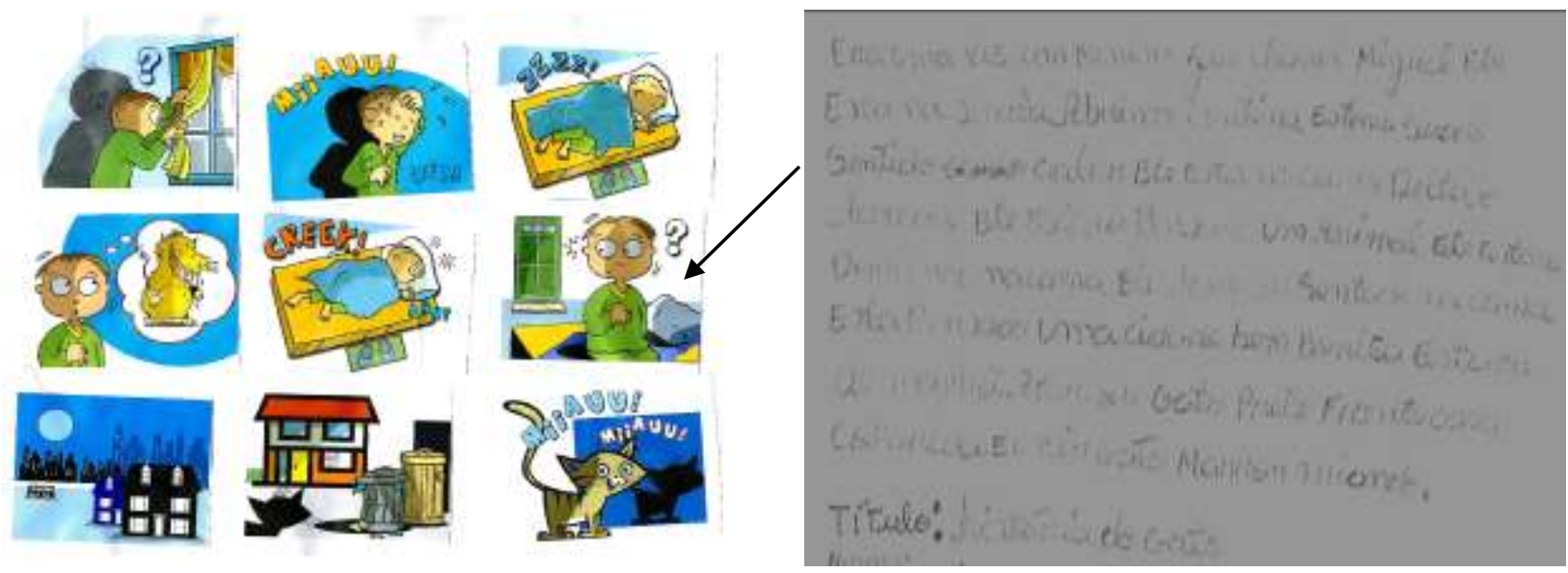

Fonte: Arquivo das pesquisadoras (2020). 
Figura 4 - Produção textual

Era uma vez um menino que chama Miguel Ele Esta na Janela Abrindo contina Estava Suado Sentindo calor Ele esta na cama Deitado Acordado Ele Estava Pensado um Animal Ele estava Dormindo na cama Ele Acordou Sentado na cama Esta Pensado uma cidade bem Bonita Estava de manhã Apareceu gato Preto Frente casa Colorida Eu vir gato Marron miando.

Título: história do gato

Fonte: Arquivo das pesquisadoras (2020).

Após a disposição das nove imagens na mesa, as duplas analisaram cada cena e definiram a ordem da história. Encerrada essa etapa, iniciaram a escrita do texto que intitularam, respectivamente, de "Uma noite assombrada" e "História do gato". A escolha dos títulos foi bastante pertinente, já que os acontecimentos expressos nas imagens se deram no período noturno e de fato o personagem principal da história viveu um momento de suspense. Além disso, é importante destacarmos que o gato foi o elemento que desencadeou todo o suspense da trama. As histórias foram iniciadas com "Era uma vez" que constitui uma frase bastante comum nos textos do gênero narrativo, demonstrando que as participantes tiveram ou têm contato com histórias infanto-juvenis. Esse dado evidencia que a produção textual é o resultado da interação do sujeito-autor com as suas vivências, uma vez que ele reúne pré-conhecimentos, conviç̧ões e intenções para alcançar o objetivo sociocomunicativo $(\mathrm{KOCH}, 2014)$. O dado apresentado também possibilita a reflexão de que é necessário apresentar outras formas de início de narrativas para que a pessoa com SD possa ampliar seu repertório linguístico já que demonstram, claramente, essa capacidade.

No que diz respeito ao princípio da continuidade, percebemos que os dois textos garantiram a coerência macroestrutural uma vez que as jovens não perderam "o fio da meada" e conseguiram desenrolar os acontecimentos. No nível da coesão microestrutural, percebemos que AA e MM não conseguiram empregar pronomes, artigos e substituições lexicais para retomar elementos. Já no texto de LA e MO, percebemos a presença do pronome pessoal do caso reto "ele" que retomou a palavra "menino". Em relação à concordância de gênero e número, notamos que houve o emprego correto como, por exemplo, em "ele estava" e "o garoto escuta". Conforme Bernárdez (1982), o texto precisa seguir os critérios no nível textual e linguístico, pois as palavras não possuem significados isolados e necessitam de uma rede de sentidos. Sendo assim, consideramos que os textos produzidos pelas jovens são compostos por frases articuladas entre si que 
LADEIA, R. T. L.; BOARETTO, G. C.; GHIRELLO-PIRES, C. S. A.

culminam em um todo coerente.

Para Costa Val (2006, p. 21), "avaliar a continuidade de um texto é verificar no plano conceitual se há elementos que percorrem todo o seu desenvolvimento, conferindoIhe unidade; e, no plano linguístico, se esses elementos são retomados convenientemente pelos recursos adequados". Sendo assim, percebemos que as palavras "garoto", também referenciado como "Miguel" e "Ele"; bem como "menino" estão nos textos evidenciando que são os personagens principais das histórias. Apesar da deficiência intelectual, esse fato demonstra que as jovens conseguiram selecionar e organizar palavras observando as regras de notação escrita, assim como foi evidenciado na produção escrita de alguns sujeitos que participaram da pesquisa de Gomes (2013).

O princípio da progressão ocorre quando o produtor do texto consegue "ir para frente", ou seja, apresenta novos fatos. Notamos que nos textos produzidos pelas participantes esse princípio se faz presente, já que há uma apresentação progressiva dos acontecimentos: "garoto escuta um barulho estranho e acorda e se levanta", como também no trecho: "Ele esta na cama deitado acordado Ele estava pensado um animal". É importante ressaltar que nas construções orais/escritas de pessoas com síndrome de Down, identificamos o estilo telegráfico (ABAURRE; COUDRY, 2008), isto é, ausência de preposições, conjunções, artigos etc.

Em nossa análise consideramos que a utilização do estilo telegráfico, mesmo em idade mais avançada e com jovens escolarizados, se deve não só por fatores inerentes aos sujeitos, como o atraso no processo de aquisição e desenvolvimento da linguagem, mas também por fatores sociais e interacionais relacionados às oportunidades oferecidas a esses sujeitos, como, por exemplo: a) não há incentivo para que esses alunos permaneçam nas escolas e avancem para além do ensino fundamental; b) a escola não cobra dessas pessoas a apropriação de conceitos mais específicos e elaborados no que diz respeito à língua portuguesa, pois o mínimo que eles produzem é considerado suficiente para a aprovação; c) a análise das atividades desenvolvidas por essas jovens que participam do grupo de pesquisa "Fala Down" indica uma carência de atividades na modalidade escrita de linguagem.

Também foi considerada em nossa análise a ausência dos sinais de pontuação. 0 progresso na utilização desses recursos gramaticais acontece, gradualmente, para todas as pessoas em processo de alfabetização e pode ser aprimorado com o emprego de tais 
sinais nas atividades de escrita e de leitura.

Outro fator observado em nossa análise foi o princípio da não contradição que é alcançado à medida que as palavras empregadas se juntam de modo a não contradizer as ideias ditas anteriormente, por isso é tão importante utilizar um vocabulário que já domina, evitando sentidos controversos. Nos textos em análise, percebemos que não houve uma contradição dos fatos nem houve emprego inadequado de palavras que provocam esse efeito (CHAROLLES, 1988). Contudo, notamos uma limitação dos recursos linguísticos, tendo em vista que não identificamos construções sintáticas complexas, mas construções com o emprego da ordem direta do discurso. Para Costa Val (2000), a não contradição também depende do interlocutor, já que o conhecimento de mundo e a aceitabilidade vão interferir na compreensão do texto.

Relacionado ao princípio da não contradição, merece ser destacado o fato de que no texto produzido por LA e MO, elas narram "estava de manhã", contudo, se observarmos a gravura, veremos que há uma lua indicando que já era noite. Essa supressão de pequenos elementos durante a análise da gravura também é comum em pessoas com SD, pois há uma tendência à identificação do todo e não das partes (MILLER, 1996). Corroborando com o pensamento do autor, Horstmeier (1995) afirma que, apesar de os elementos visuais constituírem pistas importantes para compreensão, as pessoas com SD têm dificuldade de realizar associações completas e análises mais detalhadas.

Ainda em relação ao princípio da não contradição, no trecho do texto produzido por AA e MM: o "garoto imagina que é um monstro da porta", as participantes justificaram, no momento da socialização oral do texto, que a história aconteceu em uma noite de lua cheia e, nesse período, costuma ter muita ventania. Sendo assim, é comum que a porta do quarto faça alguns barulhos por conta do impacto do vento, levando o garoto a concluir que era "um monstro da porta". Esse comentário revela que o texto não é apenas uma organização de palavras, mas traz as intenções do autor (COSTA VAL, 2006) e precisa cumprir o seu papel sociocomunicativo (ANTUNES, 2010).

Por fim, temos a articulação que deve garantir uma ligação entre as informações textuais, ou seja, a escolha dos recursos linguísticos deve manter a coerência do texto. Para tanto, recorremos aos conectores e articuladores a fim de sinalizar as relações semânticas. Em ambos os textos, evidenciamos que as ideias são ligadas pela conjunção coordenativa aditiva " $e$ ". A conjunção foi empregada de modo adequado, conforme as 
regras da gramática normativa, entretanto, a presença de outros conectivos concederam ao texto uma maior variedade e uma sequência de leitura mais fluída. Essa dificuldade de combinar palavras de ordem qualitativa e não quantitativa é uma característica dos sujeitos com SD, por isso é tão importante a estimulação com textos para que possam compreender as normas de combinação linguística (TRISTÃO; FEITOSA, 1998).

Além disso, é importante considerar que no texto de AA e MM houve a identificação dos acontecimentos marcados pelas onomatopeias, ao escreverem: "o garoto escuta um barulho estranho" ( $2^{\circ}$ quadro), "garoto fica com a expressão aliviado e volta a dormir tranquilamente" ( $8^{\circ}$ e $9^{\circ}$ quadros). Dessa forma, destacamos a coerência entre o texto verbal e o não verbal e confirmamos que o texto é um lugar de interação, construção e reconstrução de conhecimento (MARCUSCHI, 2012).

Diante do exposto, concluímos que as produções escritas atenderam aos requisitos necessários para garantir a coerência e coesão textual, pois o resultado mostrou que "numa determinada situação social, dois ou mais sujeitos, interagem; produzem juntos uma peça de comunicação" (ANTUNES, 2009, p.79), enfatizando que o texto deve constituir uma unidade semântica, fundamentada com os recursos linguísticos e deve cumprir o seu papel sociocomunicativo.

\section{Conclusão}

A linguagem possui um caráter interlocutivo e, por isso, favorece as relações de interação entre os seres humanos. O autor/locutor precisa reconhecer o caráter interacional do texto para que possa construir, conscientemente, os parágrafos dotados de sentido. Sendo assim, a atividade proposta pelas colaboradoras do Grupo de Pesquisa "Fala Down" permitiu que as participantes assumissem o papel de locutoras e escrevessem o texto a partir dos conhecimentos que possuíam da relação homemmundo.

As jovens AA e MM demonstraram habilidade na organização das gravuras, bem como no domínio do código escrito da língua. Além disso, produziram o texto respeitando os princípios que garantem a coerência e a coesão textual. É importante lembrar que o nível de escolaridade de AA e MM é, respectivamente, ensino superior completo e ensino superior incompleto, justificando o bom resultado obtido na atividade.

As jovens LA e MO organizaram as gravuras de modo diferente, mas também 
conseguiram manter uma sequência lógica das ideias apresentadas. Destacamos que, apesar de o nível de escolaridade da dupla LA e MO ser, respectivamente, ensino superior incompleto e ensino fundamental incompleto, não percebemos uma discrepância na produção textual em relação a outra dupla.

Ressaltamos que em ambos os textos ainda há uma necessidade de maior domínio dos recursos linguísticos, contudo, apesar da limitação no emprego dos recursos lexicais, foi possível compreender o texto como um todo significativo.

Sendo assim, enfatizamos a necessidade de propor mais atividades que privilegiem a leitura e a escrita para pessoas com SD, pois o contato com elementos verbais e não verbais contribuem não só para o crescimento na matéria linguística, mas também para a compreensão das relações estabelecidas no campo pictográfico. $E$, se essas atividades forem mediadas por um professor e/ou adulto, as possibilidades de interação são ainda maiores, pois há uma troca do conhecimento de mundo dos sujeitos que favorece mais autonomia aos sujeitos com SD tanto na produção de textos orais quanto escritos.

É preciso salientar que compreender tais situações na produção escrita de jovens com SD representam, na verdade, indícios que podem ser trabalhados no auxílio e elaboração de estratégias para os momentos de produções textuais ao longo da sua formação acadêmica.

\section{Referências}

ABAURRE, M. B. M.; COUDRY, M. I. H. Em torno de sujeitos e olhares. Estudos da Língua(gem), Campinas, v. 6, n. 2, 171-191, 2008.

ANTUNES, I. Análise de textos: fundamentos e práticas. São Paulo: Parábola Editorial, 2010.

ANTUNES, I. Língua, texto e ensino: outra escola possível. São Paulo: Parábola Editorial, 2009.

BERNÁRDEZ, E. Introducción a la lingüística del texto. Madri: Espasa-Calpe, 1982.

COSTA VAL, M. G. Redação e textualidade. São Paulo: Martins Fontes, 2006.

COSTA VAL, M. G. Repensando a textualidade. In: AZEREDO, J. C (org.). Língua portuguesa em debate: conhecimento e ensino. Petrópolis: Vozes, 2000. p. 34-51.

CHAROLLES, M. Introdução aos problemas de coerência dos textos. In: GALVES, C. et al.(org.). O texto: escrita e leitura. Campinas: Pontes, 1988. p. 39-85. 
GOMES, A. L. L. A produção escrita de alunos com e sem síndrome de Down: uma análise da coerência textual. Educar em Revista, Curitiba, n. 47, p. 285-300, jan./mar. 2013.

GUNN, P. Speech and Language. In: LANE, D. E.; STRATFORD, B. Current approaches to Down 'symdrome. Londres: Holt, Rincharte Winston, 1985. p. 235-246.

GHIRELLO-PIRES, C. S. A.; LABIGALINI, A. P.V. Síndrome de Down: o funcionamento da linguagem. In: COUDRY, M. I. H.; FREIRE, F. M. P.; ANDRADE, M. L. F.; SILVA, M. A. (Org.). Caminhos da Neurolinguistica Discursiva: Teorização e Práticas com a Linguagem. Campinas: Mercado de Letras Edições e Livraria, 2011. p. 357-376.

HORSTMEIER, D. A. Comunicação. In: PUESCHEL, S. (org.) Síndrome de Down: guia para pais e educadores. Campinas: Papirus, 1995. p. 39-65.

KOCH, I. V. O texto e a construção dos sentidos. 10. ed. São Paulo: Contexto, 2014.

MARCUSCHI, L. A. Linguística textual: o que é e como se faz. São Paulo: Parábola Editorial, 2012.

MILLER, J. F. Desenvolvimento lexical em crianças pequenas com síndrome de Down. In: CHAPMAN, R. S. Processos de distúrbios na aquisição da linguagem. Porto Alegre: Artes Médicas, 1996. p. 121-139.

MINAYO, M. C. S. O desafio do conhecimento: pesquisa qualitativa em saúde. São Paulo: Hucitec, 2008.

SCHWARTZMAN, J. S. Síndrome de Down. São Paulo: Editora Mackenzie, 1999.

TRISTÃO, R. M.; FEITOSA, M. S. G. Linguagem na síndrome de Down. Psicologia: Teoria e Pesquisa, Brasília, v. 14, n. 2, p.127-137, maio/ago. 1998.

Submetido em: 02 fev. 2021. Aceito em: 25 jun. 2021. 